\title{
An Attempt to Modernise Customer Practice with Ration Card at Ration Shop using Advanced Electronics Technology
}

\author{
N.S. Murtisarma ${ }^{1}$, N. Pramada $^{2}$ \\ Sreenidhi Institute of Science and Technology, Yamnampet, Telangana, India ${ }^{1,2}$
}

\begin{abstract}
In this paper an attempt to use the electronic technology at fair price shop level is shown. This requires further modifications with several implications to make it in to practice. Embedded systems and keil software were used to develop a hard ware proto model to realize the concept.
\end{abstract}

Keywords: Ration shop, groceries, open market, RFID tag, GSM module, keil software.

\section{INTRODUCTION}

Public Distribution System is government administered chain of shops which distributes groceries at subsidized rates. There are about 5,00,000 ration shops across India. In India over 54 crore people are getting benefited by public distribution system. The major groceries distributed are rice, wheat, kerosene, sugar etc. Its greatest achievement lies in preventing famines in India. The objectives of Public Distribution System includes to provide groceries at low prices to the vulnerable sections of the society and to influence the price of groceries in open market. A model sample that demonstrates the difference of cost at general and fair price shops appears in Tab.1. Of course, the figures in col.3 and col4 were on an casual enquiry of the proposers with a general fair price shop.

Table1: Sample groceries to general and a customer with ration card.

\begin{tabular}{|l|l|l|l|}
\hline S.No & Item Name & Actual Price in Rs (per kg/ ltr) & Subsidized Price in Rs (kg/ ltr) \\
\hline 1 & Rice & 20 & 1 \\
\hline 2 & Wheat & 40 & 7 \\
\hline 3 & Kerosene & 38 & 19 \\
\hline 4 & Sugar & 42 & 13.50 \\
\hline
\end{tabular}

Ration card is an official document entitling the owner to a ration of groceries. One card per family is issued by the state government for people under poverty line (Say less than Rs50,000 annaual income). People having ration card can buy the groceries from ration shop for subsidized rates fixed by the Government. In the ration shop, first we need to submit the ration card and then it is authenticated. Then they will issue the quantity of groceries eligible through weighting system manually. Then they will record the details. But this system is having two draw backs, first one is chance of forgery and second no transparency to customers.

In this work, we propose ration materials distribution based on GSM and RFID Technology to avoid the drawbacks. Radiofrequency identification (RFID) based access control system allows only authorized or responsible persons to get the materials from ration shops. RFID card acts as ration card and stores the name and phone number of the customer and can avoid forgery and theft. GSM is used to communicate the information with cardholders to provide transparency.

A. Objective of attempt

- The objective of the designed system is to provide transparency and avoid forgery in ration shops.

- Forgery can be avoided by Radio Frequency Identification (RFID) technology which replaces conventional ration cards by RFID tags .

- The microcontroller sends the information to customer using Global System for Mobile (GSM) technology which would create transparency in the system. 


\section{International Journal of Advanced Research in Computer and Communication Engineering \\ ISO 3297:2007 Certified \\ Vol. 6, Issue 4, April 2017}

B. A note on System at practice

India's Public Distribution System (PDS) is the largest distribution network in the world. The responsibility of distributing food grains lies with the government. The major groceries distributed are rice, wheat, kerosene....etc. The main objective of Public distribution system is to provide groceries at low prices to the vulnerable sections of the society and to influence the price of groceries in open market. Public Distribution System (PDS) faces the challenges like quality of food grains and inaccurate identification of ration card holders. In the existing system one ration card per family is issued by the state government for people under poverty line. Ration card holders will buy the groceries from ration shop for subsidized rates fixed by the Government .Each family under poverty line is eligible for $15 \mathrm{~kg}$ of food grains. In the ration shop, first we need to submit the ration card and then it is authenticated. Then they will issue the quantity of groceries eligible through weighting system manually. Then they will record the details. This method is inaccurate, tedious and may sometimes result to malpractices.

\section{LITERATURE SURVEY}

The existing predictable ration system has the basic issues of renewing the ration card every year by the employees to the malpractices done by the ration store dealers like diverting food grains to open market to make profit. To tackle this problems K.Balakarthik (2013) describes the development of a cloud-based ration card system using Radio Frequency Identification (RFID) technology. The existing conventional ration card system has numerous problems. These problems ranges from the basic issues of renewing the ration card every year by pasting excess leaves which has to be done manually by the employees to the malpractices done by the ration store dealers like diverting food grains to open market to make profits. There is another problem of irregularity in opening shops and false announcements of deficit in food grains. All the above problems in the existing ration card system can be tackled by this proposed ration card system using RFID. The user can buy whatever he wants by just flashing the ration card at the RFID reader at the ration store. The user authentication is done by sending a random password text to the user mobile which has to be entered in a keypad. The purchase is validated by the employee only after the details are entered in a windows application which is connected to the cloud which stores the user personal and purchase information. Above all the user can always check their purchase details in a dedicated website. A.N. Madur.etal (2016) proposed an Automatic Ration Materials Distribution Based on GSM (Global System for Mobile) and RFID (Radio Frequency Identification) technology instead of ration cards. To get the materials in ration shops need to show the RFID tag into the RFID reader, then controller check the customer codes and details of amounts in the card. After verification, these systems show the amount details. Then customer need to enter their required materials by using keyboard, after receiving materials controller send the information to government office and customer through GSM technology. In this system provides the materials automatically without help of humans[2,3]. Here each customer is provided with RFID cards. In this system, first user is authenticated, and then system shows the balance of person. User have to enter the amount of $\mathrm{Kg}$ he want to withdraw. If the user will have sufficient balance to withdraw the current amount, system will open the valve. Through valve grain will come and it will get weighted by weight sensor. Once the count reached the entered amount controller automatically shut down the valve and updates the account of the customer. The updated account information is send to the customer's mobile using GSM. Rationing distribution is one of the widely provocative issue that involves wrong entries in stock register of shop containing wrong stock information of the products that is supplied to the public, so Rajesh C. Pingle et.al. (2013) replaced the conventional ration card by smart card in which all the details about users are provided including their AADHAR (social security) number which is used for user authentication. This prompted author(s) to interface smart card reader (RFID Based)to the microcontroller (AT89C51) and $\mathrm{PC}$ via RS232 to develop such a system. Using such a sytem, Government would have all required control/monitoring over the transactions at ration shop. To involve Government in the process we proposed connecting the system at ration shop to a central database (provided by Govt.) via GSM module (SIM900D) and RS232. S. Sukhumar et.al. (2013) proposed concept to replace the manual work in public distribution system. The ration distribution system is automated by using PLC, which is similar to the ATM. This automated ration system replaces the conventional ration card system by smart card. In addition, the finger print detector is placed in the machine in order to check the correct user access. If the user is correct user, the next process takes place and the input can be given in the touch screen. As soon as the input is given, the products are obtained from the automated ration shop and the amount is taken from the bank account of the particular person. The embedded controller is preprogrammed in such a way to perform the similar operations. In this automated ration shop government have control over all transaction that occurs in ration shop. In order to involve government in the process, the proposed ration shop system is connected to the government database via GSM modules, which further sends the up-to-date information to the government and the consumer. For the efficient operation and economic constraints of the system, the power supply unit is fully made alternate to solar power. [5][6][7][8][9][10][11]. 
These works motivated for a small attempt as outlined below. RFID tag replaces the ration cards in this project. We are storing the name and phone number of the customer in the rfid tag. Due to low memory of microcontroller details of only three customers are stored. When the tag is read by the rfid reader name and phone number of the person is displayed on the LCD screen. Then the required product and quantity has to be given through keypad. Immediately a message is sent to the customer through GSM. We can store all the details of the customer like aadhar number, annual income, family details etc in the tags. Because of the memory constraint of microcontroller, we are having only three ration card holders. This memory constraint can be eliminated by using servers having large memory to store customer's information. When there is shortage of groceries at ration shop immediately information can be sent to authorities by short message service. We can also create a website to display the details of customers and the groceries they took.

\section{PROJECT DESIGN}

The execution of the venture configuration can be partitioned in two sections.

\section{- Hardware usage}

- $\quad$ Firmware usage

Hardware utilization deals in drawing the schematic on the plane paper according to the application, testing the schematic blueprint over the breadboard using the diverse IC's to find if the diagram meets the objective, doing the PCB configuration of the schematic attempted on breadboard, finally setting up the heap up and testing the made gear.

The firmware part deals in programming the microcontroller with the objective that it can control the operation of the IC's used as a piece of the execution. In the present work, we have used the Orcad layout programming for PCB circuit arrange, the Keil $\mu \mathrm{v} 3$ programming change gadget to create and total the source code, which has been made in the $\mathrm{C}$ vernacular. The Proload programming engineer has been used to make this join code into the microcontroller. The firmware utilization is cleared up in the accompanying segment.

The $r$ plan and rule are cleared up in this part using the piece outline and circuit chart. The square blueprint discusses the required parts of the arrangement and working condition is cleared up using circuit diagram and system wiring graph.

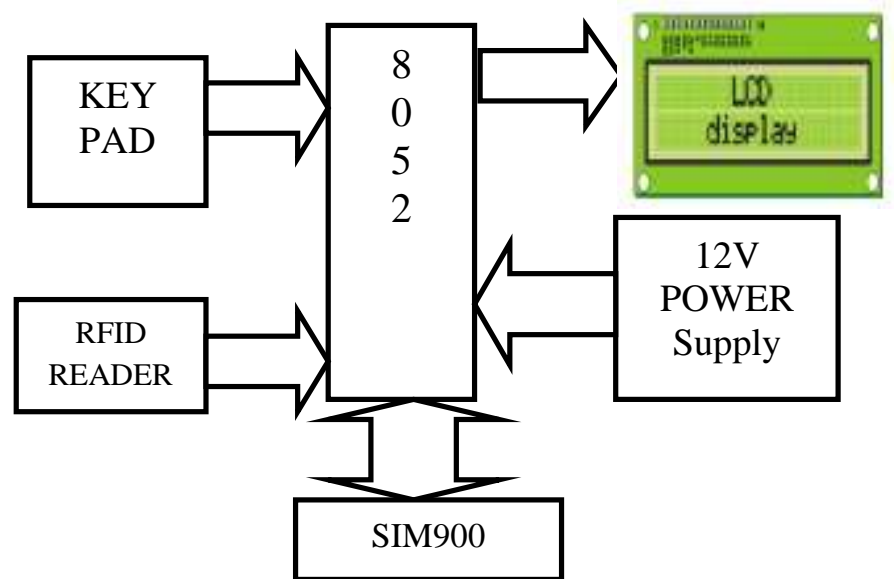

Figure 1: Block Diagram

AMTEL 8052, Microcontroller, A numeric 4x3 key pad to enter the option of grocery and its weight. Basic 16x2 LCD display, RFID module (EM-18 at $125 \mathrm{KHz}$ ). GSM (SIM900) module is the constituents used for the work.

\section{A. Outline of the hardware and firm ware implementations}

The block diagram of the design is as shown in Fig.1. It consists of power supply unit, microcontroller, GSM, keypad, RFID and MAX232 and LCD. The brief description of each unit is Shown in Fig.1.

Following steps are used while implementing project in keil software. The result blocks etc are highly common. Hence they are edited.

1. Click on the Keil uVision Icon on Desktop. Look for a template.

2. Click on the Project menu from the title bar 
3. Then Click on New Project

4. Save the Project by typing suitable project name with no extension in your own folder sited in either C:\or D:।

5. Then Click on Save button .

6. Select the component for your project. i.e. Atmel......

7. Click on the + Symbol beside of Atmel

8. Select AT89C51 as shown below

9. Then Click on "OK" abd

10. The Following fig will appear

11. Then Click either YES or NO.........mostly "NO"

12. Now your project is ready to USE

13. Now double click on the Target1, you would get another option "Source group 1"

14. Click on the file option from menu bar and select "new"

15. The next screen will be as shown in next page, and just maximize it by double clicking on its blue boarder.

16. Now start writing program in either in "C" or "ASM"

17. For a program written in Assembly, then save it with extension ". asm" and for "C" based program save it with extension ".C"

18. Now right click on Source group 1 and click on "Add files to Group Source"

19. Now you will get another window, on which by default " $\mathrm{C}$ " files will appear.

20. Now select as per your file extension given while saving the file

21. Click only one time on option "ADD"

22. Now Press function key F7 to compile. Any error will appear if so happen.

23. If the file contains no error, then press Control+F5 simultaneously.

24. The new window is as follows

25. Then Click "OK"

26. Now Click on the Peripherals from menu bar, and check your required port as shown in fig below

27. Drag the port a side and click in the program file.

28. Now keep Pressing function key "F11" slowly and observe.

29. You are running your program successfully

\section{ALGORITHM OF THE WORKING OF SCHEME}

Initial conditions of variables ; Validity of $\operatorname{card}(\mathrm{Y})(=1$ for invalidity) ; $\mathrm{X}=\operatorname{limit}$ of product( 1 if indent exceeds consuming limit of customer per month.) The steps are written for end protomodel to work. Its same display is shown in result section. Before execution of the process, it was understood that the RFID issued to a customer is with sufficient details of his personel and family details. Validity is mentioned in the algorithm that is about the fitness of the card to the shop where this scheme is being at practice.

A. Start

B. Intitalise all devices GSM,LCD and RFID reader.

C. Take RFID of customer and Read it using card reader.

D. Read variable Y. If details invalid reject. Inform if he belongs to other fair price shop. For a valide customer proceed. Repeat $\mathrm{C}$ to $\mathrm{D}$ if $\mathrm{Y}=1$; If $\mathrm{Y}$ is not equal to1 proceed.

E. Customer now chooses the grain and its quantity. This could be entered in to system. Here all his requirements can be entered And read the variable $X$. This checks if customer demand is over his limit of th card. If $x=1$, then customer's request is rejected and ask to modifiy the quantitiy. This could be carried out for all his other requirements.. This is continue if $\mathrm{x}$ is not equal to1.

F. Now, sms is initiated to customer mobile to procure the ordered grains on payment. rof customer is closed. Next customer is invited and steps from $\mathrm{C}$ to $\mathrm{F}$ are executed.

This algorithm is presumed that all the items listed in the notice board are with sufficient stock.

\section{RESULTS AND DISCUSSION}

The Electronic Distribution Of Goods In Ration Shop depends on GSM and RFID Technology which is utilized for Ration materials dispersion in proportion shops. At first everybody will be given a RFID Card, rather than a proportion card. In the 
event that the client needs to get any apportion material, the client needs to demonstrate the proportion RFID label card to the RFID per user, the per user will perceive the RFID numbers appear by the client. Every client will have a novel number, which is not noticeable to the client. This perceived RFID number will be given to a microcontroller, which contrasted the info number and the database. Before beginning the framework, the exceptional RFID number of the apportion client will be customized in the controller, for example, User name and secret key, so that the controller will perceive the information originating from RFID by contrasting and the database. Once the client is distinguished, the apportion things to be administered will be shown on the LCD screen, the client needs to bolster the remarks, for example, the weight he will purchase. As the apportioning procedure is going on all the while the controller will send a charge to GSM Modem, to send the content SMS to the client about the proportion thing, he or she obtained.

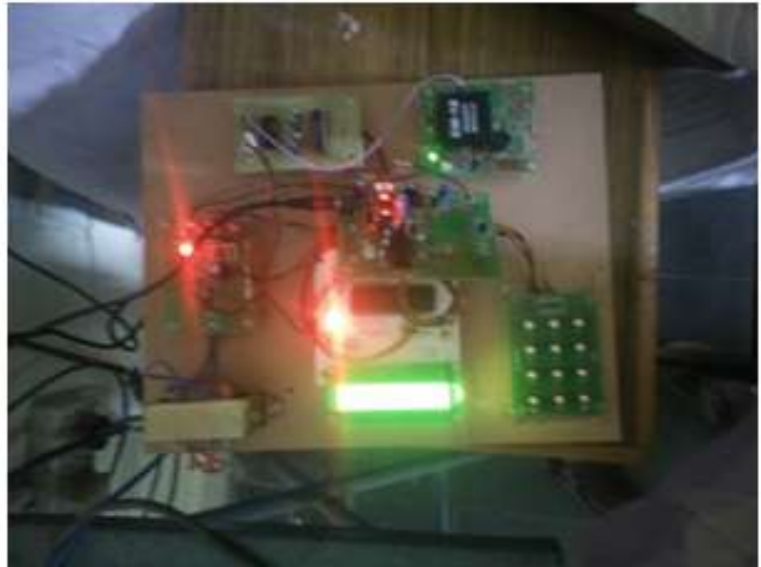

Figure2: Prototope model of system

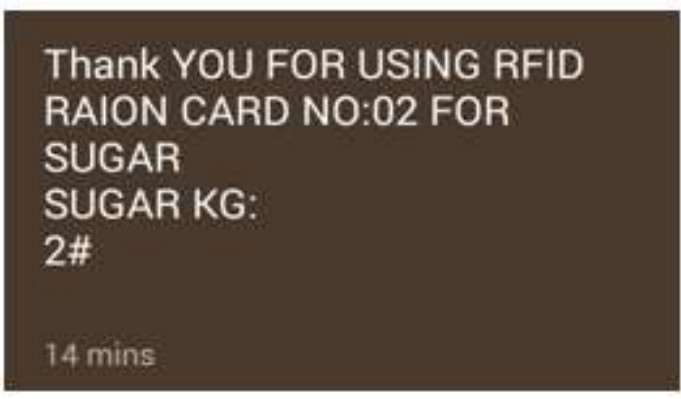

Figure 3: Display after eustomer's service.

\section{CONCLUSION}

The work is drafted from the work of the group of undergraduated final year students. The proportion card is supplemented by brilliant RFID card and client is verified. If this is at success, Loose of card at unusual conditions may not penalize the benefiter of the scheme.. This could be with further extension that incorporating the details of stock of groceries that displayed in the list and to take a decision of placing the order for consumed groceries to the suppliers can also be done. Advantages of the attempt are mostly time viable approach. This framework is exceptionally successful, precise, straight forward and control moderate... This framework promises keeps up information accuracy.

\section{REFERENCES}

[1]. Balakartik, "Cloud-Based Ration Card System using RFID and GSM Technology," International Journal of Engineering Research \& Technology,Vol.2, issue4, April,2013.

[2] Sham Nayse, and A.N. Madur, “Automation in Rationing System using Arm 7”, IJIREEICE, Vol. 1, Issue 4, pg. 2321 - 2004 , July 2013

[3] Valarmathi,S,Ramani, Fahim Aktar, Selvaraju and Ramachandran, "Automatic Ration Material Distributions Based on GSM and RFID", DOI: 10.5815/ijisa.2013.11.05, I.J. Intelligent Systems and Applications, Vol.11 ,47-54, 2013.

[4] Rajesh C.P and P.B.Borole, "Automatic Rationing for Public Distribution System (PDS) using RFID and GSM Module to Prevent Irregularities", Int. J. of Technology Innovations and Research,Vol.2, March,2013.

[5] Mouly, M., and M. B. Pautet, ”The Global System for Mobile Communications," Telecom publishers, 1992.

[6] Vinayak T. Shelar, Mahadev S. Patil,"RFID and GSM based Automatic Rationing System utilizing LPC2148", International Journal of Advanced Research in Computer Engineering and Technology (IJARCET) Volume 4 Issue 6, June 2015.

[7] R. Parthipan, K. Sreenivas, "A Systematic Application for Public Distribution-Ration Shop", International Journal of Innovative Research in Computer and Communication Engineering Vol.3, Special Issue 6, August 2015.

[8] Abdul H. Ansari, KetanG. Badgujar, Monali R. Rathi, Shital R. Tambe, "Mechanization in proportioning framework utilizing RFID and GSM innovation" International Journal of Engineering, Education and Technology, volume 3, issue 2, 2015.

[9] Kashinath Wakade, Pankaj Chidrawar, Dinesh Aitwade, "Shrewd Ration Distribution and Controlling" International Journal of Scientific and Research Publications, ISSN 2250-3153, Volume 5, Issue 4, April 2015.

[10] Jaid Rahul A, Kadam Chetan K, Kokare Aniket S, Deore Minal, "An Overview of Automatic Rationing System", International Journal of Informative and Futuristic Research, ISSN 2347-1697, Volume 2 Issue 6 ,February 2015.

[11] Miss. Manisha M. Kadam, Miss. Smita R. Jagdale,Miss Arati A. Lawand, Miss. Shraddha J. Chavan, "Microcontroller Based Efficient Ration Distribution System", International Journal. For scientific research and development, Volume: 3, Issue : 2, 1401-1404, Jan2015. 